\title{
SUSTAINABLE MOBILITY FOR HEAVY FREIGHT VEHICLES
}

\author{
R. HASSAN \& K. McMANUS \\ Faculty of Engineering and Industrial Sciences, Swinburne University of Technology, Australia.
}

\begin{abstract}
Mobilisation of heavy freight vehicles in a sustainable manner requires providing accessibility and a welldefined, safe and smooth road network that allows short travel times to minimise the carbon foot print of heavy transport system. Road surface roughness affects the comfort of the driver and increases user costs in terms of vehicle operating costs and travel time. Achieving a smooth road network requires adopting appropriate maintenance and rehabilitation strategies. The latter requires the use of appropriate intervention criteria in terms of intervention measures and treatments. This paper describes the development and validation of a profile-based roughness measure referred to as the Heavy Articulated Truck Index (HATI). HATI can be used to identify road sections providing poor ride quality for heavy transport operators. The effectiveness of HATI as a measure of pavement damage due to dynamic wheel loads is also investigated. Adopting HATI and the other diagnostic measures proposed herein help road authorities implement appropriate maintenance strategies to ensure the sustainability of their pavement assets and reduce emissions generated by heavy and light vehicles, in addition to providing acceptable level of service to all road users.

Keywords: dynamic wheel loading, expansive soils, heavy vehicles, road roughness, vibration.
\end{abstract}

\section{INTRODUCTION}

Freight movement in Victoria and Australia is largely done by road travel, so providing a network with good ride quality for heavy freight vehicles is crucial to the economic development of the state and the country. The state road authority of Victoria, Vicroads, normally uses the International Roughness Index (IRI) to identify sections in their road network with poor ride quality. They use the IRI as the measure to trigger maintenance intervention in their pavement management system (PMS) to improve rideability and reduce user costs. However, a number of studies [1-4] have indicated that the IRI is not suitable for characterising pavement rideability for heavy vehicle occupants. This was confirmed through anecdotal instances reported by heavy transport operators, where they complained about the rideability of road sections with IRI values much lower than the intervention level ( $\geq 4 \mathrm{~m} / \mathrm{km}$ for major freight routes).

This paper describes the outcomes of a research project sponsored by Vicroads to address the problem of pavement rideability as perceived by heavy freight transport operators. The aims of the project are:

- to identify road surface characteristics that affect driver comfort and perception of pavement ride quality on Victoria's rural arterial network; and

- to develop a profile-based roughness measure that can be used in their PMS to highlight sections with poor ride for heavy vehicle drivers at network level.

The aim of this paper is to report on the development and validation of a new roughness index called the Heavy Articulated Truck Index (HATI) and its effectiveness in identifying sections providing poor ride quality to heavy vehicle occupants and as a predictor of pavement damage due to dynamic wheel loads.

\subsection{IRI as a measure of truck ride}

The reason that the IRI is not suitable as a measure of truck ride is that it represents the vertical response of a passenger car to road input, which is different to truck response. Fig. 1, Cebon [5] shows 


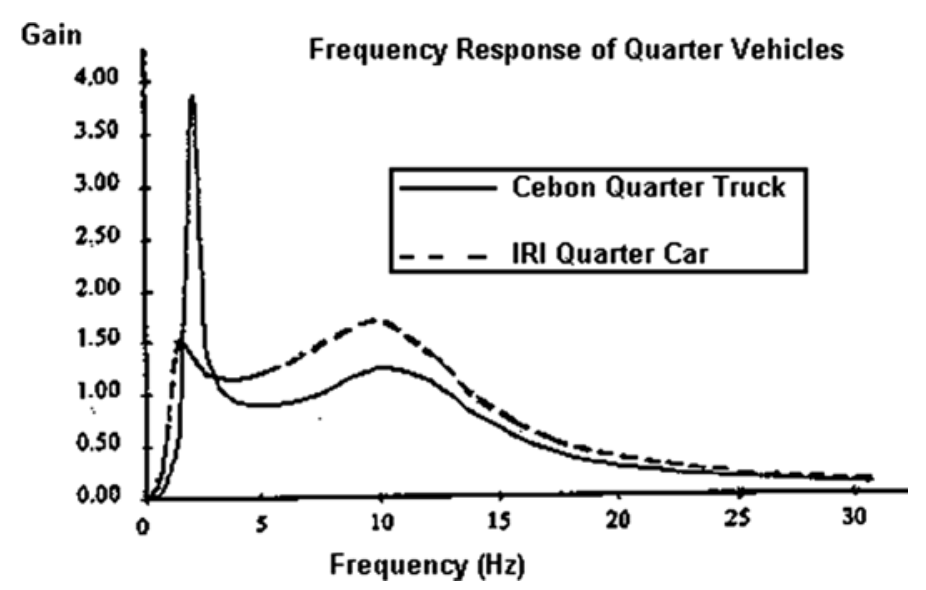

Figure 1: Frequency response functions of quarter truck and car models to road input [5].

a comparison between the vertical responses to road input of a quarter truck model (QTM) and the quarter car model (QCM) used in calculating the IRI. It can be clearly noticed that both response functions have two peaks at the same excitation frequencies but with different amplifications i.e. gains. The QTM is much more responsive (high gain) at the low frequency peak, which corresponds to excitation of the body bounce vibration mode, and less responsive at the high excitation frequency of axle hop. The opposite is true for the QCM. Low frequency vibration modes of the truck body are excited by the longer wavelengths of the roughness spectrum $(>3 \mathrm{~m})$ and the high frequency ones are excited by the medium and short ones $(<3 \mathrm{~m})$. The latter is the result of deterioration in the upper layers of the pavement and the first develops as a result of heave and subsidence of expansive soil subgrade due to seasonal moisture variation, or settlement of soft soils.

\subsection{Road characteristics and truck ride}

Road surface irregularities with different lengths and amplitudes excite several vibration modes of the truck body at different frequencies and magnitudes. The resulting motions detract from driver comfort and perception of pavement ride quality. Road characteristics that may affect truck ride include the following:

- Elevation variation within the wheel paths, which induces vertical motions due to excitation of the truck body bounce, body pitch and axle hop vibration modes. They may also result in longitudinal (fore/aft) motion due to excitation of body pitch and frame bending modes. These modes occur at frequencies between 1.5 and $10 \mathrm{~Hz}$.

- Roughness variation between the wheel paths, which induces sideway and longitudinal motions due to excitation of the truck body roll and pitch vibration modes, respectively.

- Variation in road crossfall, which excites truck body roll vibration mode and results in sideways and rotational motions. Body roll occurs at frequencies below $1 \mathrm{~Hz}$.

This implies that an optimum truck ride measure should be capable of capturing all these motions. However, the findings of surveys of whole body vibration (WBV) exposure levels experienced by Australian heavy vehicle drivers indicated that the weighted vertical vibrations are the 
dominant ones $[1,6]$. The highest measured vertical accelerations on rural arterials in Victoria occurred in the range of $1-4 \mathrm{~Hz}$ as can be observed in Fig. 2 [1]. The magnitudes of these accelerations are so high that they affect driver comfort and perception of ride, although the human body is most sensitive to vertical vibration in the frequency range of $4-10 \mathrm{~Hz}$ [7]. These results indicate that road input in the high frequency range is being successfully attenuated by vehicle and suspension design. Accordingly, it is reasonable to assume that a measure that characterises vertical vibrations of a truck in the frequency range of $1-4 \mathrm{~Hz}$ could be a good indicator. At normal highway speeds $(60-100 \mathrm{~km} / \mathrm{h})$, these low frequency modes are excited by long roughness wavelengths in the range of 4-27 $\mathrm{m}$. The wavelength $(\mathrm{m})$ equals the speed (length per second) divided by the frequency (cycles per second).

\section{DEVELOPMENT OF HATI}

This section provides a brief description of the subjective assessment survey conducted to identify road surface characteristics that affect the comfort and perception of heavy vehicle drivers on rural arterials in Victoria. Also provided are the analysis method, results and details of the HATI model and scale.

\subsection{Subjective rating survey}

HATI was developed using a subjective rating survey of the ride quality of 27 sections from two major freight routes in rural Victoria/Australia. The test sections ranged in length between 200 and $1000 \mathrm{~m}$ and covered different levels of roughness ranging between 1.11 and $4.24 \mathrm{~m} / \mathrm{km}$ IRI. Most of Victoria's rural highway network comprises spray-sealed thin granular flexible pavements founded on expansive subgrade soils with different reactivity levels and lie in different climatic regions. Hence the test sections were selected to cover a wide range of soil reactivity/climate combinations. They have straight and flat alignments and are situated in $100 \mathrm{~km} / \mathrm{h}$ speed zones. The test vehicles consisted of prime-mover semi-trailer combination units with different properties such as suspension system, cabin configuration and age.

The ride quality of each section was rated by a panel of 10-15 heavy vehicle drivers. The drivers performed the rating exercise during their normal transport operations. The rating scale used in the subjective assessment survey ranged between zero ( 0 ) for extremely poor to 5 for perfect as shown in Fig. 3.

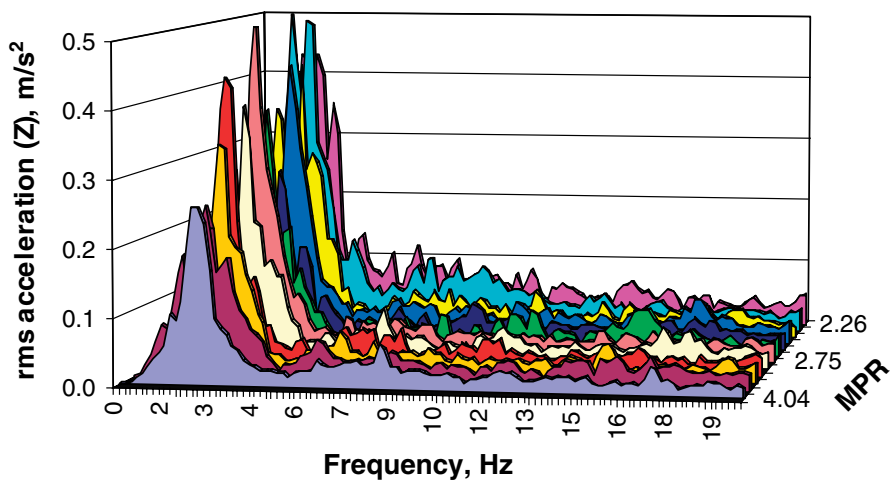

Figure 2: Acceleration spectra in the vertical direction measured on the driver seat. 


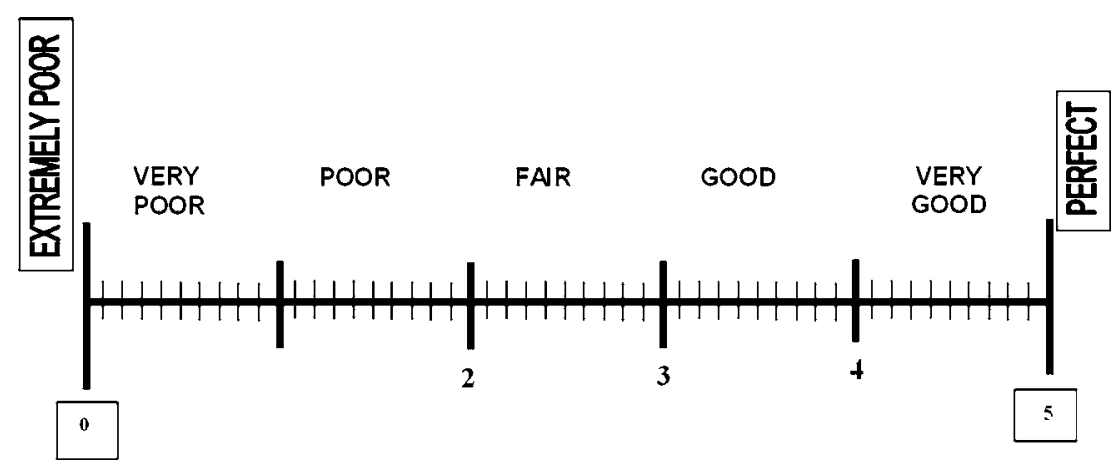

Figure 3: Rating scale used in the subjective rating survey.

\subsubsection{Reliability of ratings}

The reliability of drivers' ratings was tested for the whole data set. The measure of reliability and agreement between the raters used is Ebel's intraclass correlation coefficient (ICC) [8]. The ICC gives the reliability of the average rating for all the judges and is used as the appropriate measure of reliability when the ratings of the judges were averaged to form a score for each section as the case herein. The ICC was calculated using the results from one-way analysis of variance (ANOVA), which included the between subjects variance (between groups) and the error variance (within groups) [8]. One-way ANOVA was performed on the whole data set using the ratings as the dependent variable and roughness (IRI) of the test sections as the independent variable. The value of ICC calculated from ANOVA output is 0.89 , which indicates that there is very good agreement between the different drivers.

\subsection{Data analysis}

Data analysis involved applying power spectral density (PSD) function to the longitudinal surface profile data of the test sections and calculating roughness contents in different wavebands of the roughness spectrum, represented by the root mean square (RMS) index. The latter represents the area under the PSD curve within the roughness waveband of interest. This index is computed by integrating the PSD function and applying a weighting function. A weighting of one was assigned to the band of interest and a weighting of zero to the remainder of the spectrum.

RMS values of the different sections were then correlated to the corresponding subjective data to identify the roughness waveband that highly influences drivers' perceptions of pavement ride quality i.e. the waveband with the highest correlation coefficient. The subjective measure that was used is the mean panel rating (MPR), i.e. the sum of individual ratings for each test section divided by the number of raters for that section.

The analysis results showed that truck drivers mainly object to sections with high contents of long roughness wavelengths in the range of 5-20m. Calculating the profile-based roughness index in this waveband for a section requires performing PSD analysis, which involves performing Fast Fourier Transform Function (FFT) on the profile data of that section. The number of sampled points that can be used by the FFT must be $\mathrm{N}=2$ raised to the power of $\mathrm{I}$, where $\mathrm{I}$ is an integer from 1 to 12 i.e. a maximum total of 4100 sample points. This limitation makes the calculation of a profile-based index using PSD analysis not feasible for managing pavements at network level. The reason is that the 
profile data is stored in an average length of $15 \mathrm{~km}$, equivalent to approximately 400,000 sample points at $0.0401 \mathrm{~m}$ sample interval.

Accordingly, attempts were made to develop another index using an analysis method other than PSD. The latter involved applying different types of filters covering the roughness waveband of interest and weighting functions to road surface profile data of the test sections. MPR values were then correlated with the different profile-based roughness measures. HATI filter proved to be the best measure with a correlation coefficient of -0.91 , compared with -0.82 for IRI.

\subsection{HATI model and response function}

HATI is a profile-based index for identifying pavement sections providing poor ride quality for heavy transport operators. It is a distance-domain index which makes it suitable for use in pavement management at network level. HATI of a road section is determined by processing the longitudinal surface profile data of the section through a quarter truck filter (QTF) with the following properties:

- Travel speed $=100 \mathrm{~km} / \mathrm{h}=27.7777 \mathrm{~m} / \mathrm{s}$

- $\mathrm{Ms}=$ Sprung mass $=1$

- $\mathrm{Ks} / \mathrm{Ms}=$ suspension stiffness $=250 \mathrm{~s}^{-2}$

- $\mathrm{C}_{\mathrm{s}} / \mathrm{Ms}=$ suspension damping $=30 \mathrm{~s}^{-1}$

- $\mu / \mathrm{Ms}=$ unsprung mass $=0.150$

- $\mathrm{Kt} / \mathrm{Ms}=$ tyre stiffness $=400 \mathrm{~s}^{-2}$

- $\mathrm{B}=$ tyre enveloping (base length) $=250 \mathrm{~mm}$

- Initialisation distance $=19 \mathrm{~m}$

The vertical response for HATI QTF to road input is shown in Fig. 4. The properties and frequency response of HATI QTF are based on those of a QTM described in Austroads [2] for a driver/seat/truck model. HATI QTF frequency response was determined by excluding the effect of the driver/seat filter. HATI captures the effects of vertical and longitudinal excitations of the low frequency body bounce and pitch vibration modes due to its sensitivity to long wavelength roughness (LWR).

HATI is easy to calculate using the same software for calculating the IRI but replacing the parameters of the QCM by those of HATI QTF. Similar to the IRI [9], HATI is calculated by converting



Figure 4: Frequency response function of HATI quarter truck model to road input. 
the profile data to slope and then filtering it through the QTF. The simulated vertical response of vehicle body (represented by the QTF) to road input, called the Profile Index (PI), is accumulated using an exponent of 2 for root mean square (RMS) slope. HATI is then determined as the average of PI values of the outer (OT) and inner (IN) wheel paths and calculated using eqn (1). HATI has units of slope, $\mathrm{mm} / \mathrm{m}$ or $\mathrm{m} / \mathrm{km}$. HATI QTF is only sensitive to excitations by LWR $>3 \mathrm{~m}$. The highest gain $(>0.9)$ occurs in the frequency range $2-3.5 \mathrm{~Hz}$, which can be excited by roughness wavelengths $8-14 \mathrm{~m}$ when travelling at $100 \mathrm{~km} / \mathrm{hr}$.

$$
\mathrm{HATI}=\sqrt{\frac{\mathrm{PI}^{2}{ }_{\mathrm{OT}}+\mathrm{PI}^{2}{ }_{\mathrm{IN}}}{2}}
$$

\subsection{HATI scale}

To give the users an indication of what HATI values mean, MPR and the corresponding HATI values were used to develop a statistical transform. This transform, called Truck Ride Number $\left(\mathrm{TRN}_{\mathrm{HATI}}\right)$, predicts MPR from the profile index, HATI (in $\mathrm{mm} / \mathrm{m}$ ), has the form shown in eqn (2) and a coefficient of determination $\left(\mathrm{r}^{2}\right)$ of 0.90 . This transform can predict drivers' perceptions of pavement ride quality with an accuracy of \pm 0.3 of a scale point at $95 \%$ confidence level. HATI is a better predictor of MPR than IRI. IRI explains $76 \%\left(\mathrm{r}^{2}=0.76\right)$ of the variation in MPR.

$$
\mathrm{TRN}_{\text {HATI }}=5 \mathrm{e}^{-255 \mathrm{HATI}^{0.92}}
$$

A scale, Table 1, for HATI values and corresponding perceptions was also developed using this transform and validated using actual drivers' ratings. The threshold value between acceptable and unacceptable ride is $1.7 \mathrm{~m} / \mathrm{km}$, which results in a TRN $\mathrm{TATI}_{\text {I }}<2.5$. These values apply to heavy articulated vehicles travelling on state highways at $100 \mathrm{~km} / \mathrm{hr}$. HATI values at other speeds are different and, similar to the IRI, scales for the different speeds need to be developed.

\subsection{Effects of vehicle and driver factors}

The effects of factors related to the drivers and vehicle properties on drivers' ratings were tested using factorial analysis of variance (ANOVA). Factors related to drivers included age, weight and years of driving experience and vehicle factors included size, age, cabin location, drive axle suspension type and loading condition. The details of the analyses can be found in [1].

The effects of these factors were found to be not significant except for cabin configuration. Cabin above engine configuration was found to provide a poorer ride than the cabin behind engine configuration [1]. However, considering that the drivers who travelled in trucks with cabins above

Table 1: HATI and TRN $_{\text {HATI }}$ scale.

\begin{tabular}{llc}
\hline HATI $(\mathrm{m} / \mathrm{km})$ & Perception & TRN $_{\text {HATI }}$ scale \\
\hline$<0.5$ & Very good & $4-5$ \\
$0.5-1.20$ & Good & $3-4$ \\
$1.20-2.20$ & Fair & $2-3$ \\
$2.20-4.0$ & Poor & $1-2$ \\
$>4.0$ & Very poor & $0-1$ \\
\hline
\end{tabular}


engines comprise the majority of the sample, this makes HATI valid for the worst cases of vehicles considered in the study. This implies that HATI is applicable for these conditions but needs to be validated for other soil/climatic conditions and truck configurations.

\subsection{Effect of subgrade soil reactivity and climate}

As mentioned earlier, the rating sections are located in expansive soil areas but with different reactivity levels and lie within different climatic conditions. Expansive soils have the potential for shrinking or swelling under changing moisture conditions. Movement in expansive soils usually occurs in an uneven pattern resulting in distortion of the longitudinal profile of the pavement surface and the development of LWR. Climate (extent of seasonal moisture variation) and soil reactivity (composition/mineralogy) influence the extent of LWR development and ultimately HATI values. The extent of soil movement is also influenced by a number of factors including permeability of pavement material, shoulder condition (sealed or unsealed), extent of gilgai formation and availability and condition of available surface and subsurface drainage.

Examination of the data showed that road sections founded on highly reactive subsoils and located in problematic climate zones are associated with high HATI values. Fig. 5 shows that HATI values for such sections (High) are higher than those of sections with similar IRI values, but overlay low reactivity subsoils and lie within climate zones that are less prone to having problems (Low).

\section{VALIDATION OF HATI}

The effectiveness of HATI in highlighting sections with poor ride quality for heavy transport operators and its applicability to other regions was validated using two data sets. The study objective and the approach adopted in addressing them are highlighted here:

- Validating HATI and assessing its applicability to other regions by establishing whether the candidate sections from the two data sets are associated with HATI values greater than the threshold $(1.7 \mathrm{~m} / \mathrm{km})$ or not.

- Identifying the characteristics of sections associated with HATI values more than threshold that may contribute to the deteriorated ride.

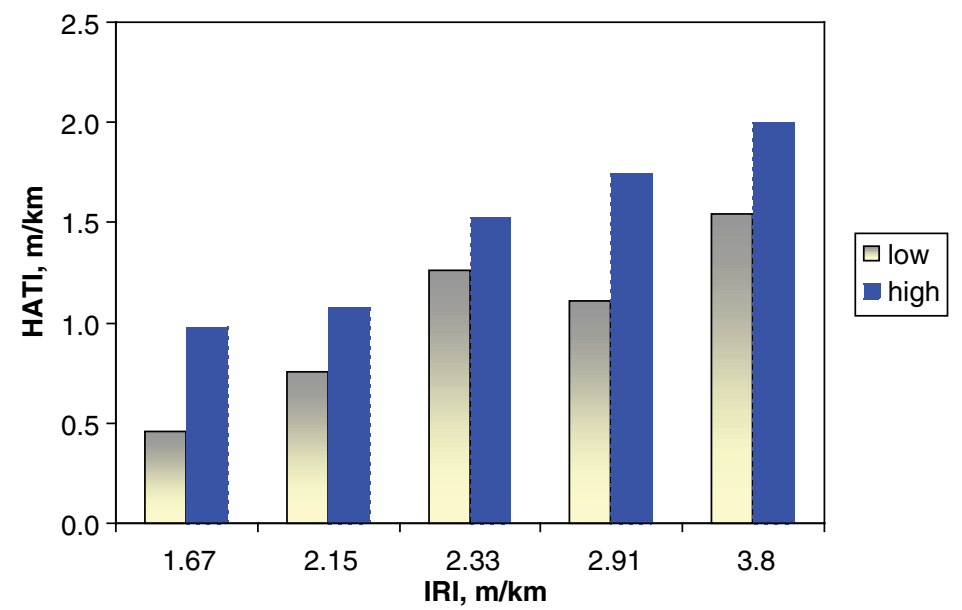

Figure 5: Effect of subgrade soil reactivity and climate on HATI values. 
The following sections provide descriptions of the two data sets, the analysis of the data and a summary of the findings.

\subsection{Description of the data sets}

The data sets included long sections from rural arterials in Victoria/Australia and from New Zealand, which included subsections that were identified by truck drivers to provide poor ride quality.

\subsubsection{Vicroads (VR) data}

Nine sections were considered in this study ranging in length between 1 and $5 \mathrm{~km}$ (a total of $209100 \mathrm{~m}$ segments). All these sections were located in expansive soil areas but with different reactivity levels and lay within a climatic region prone to having soil movement problems. The data set included raw Multi-Laser Profiler (MLP) data for these sections. Geometry data for these sections were not available.

\subsubsection{New Zealand (NZ) data}

The data included geometric and longitudinal profile data for a section of a state highway along the east coast of the South island (Canterbury and Marlborough regions) where mainly sediments (nonexpansive) make up the subgrade soil. The data also included the locations of the subsections that were identified by the drivers to provide unpleasant ride, which included seven long sections ranging in length between 1 and $12 \mathrm{~km}$ (a total of $282100 \mathrm{~m}$ segments). Geometry data included longitudinal grade and curvature for $100 \mathrm{~m}$ segments and crossfall data were reported at $10 \mathrm{~m}$ intervals.

\subsection{Validation analysis and findings}

For each data set, HATI and IRI values were calculated for every $100 \mathrm{~m}$ segment. The IRI values were also calculated for every $10 \mathrm{~m}$ sections in the outer and inner wheel paths and were then used to calculate the standard deviation of their averages (STDave) and differences (STDdiff) over $100 \mathrm{~m}$ segments. Considering wheelbase dimensions of prime mover semi-trailer combination units, $4 \mathrm{~m}$ (6.2 $\mathrm{m} \max )$ for the prime mover to about $10 \mathrm{~m}$ for trailer $(12.5 \mathrm{~m}$ max $)$, variations over $10 \mathrm{~m}$ segments were considered to be suitable. The crossfall data for NZ sections were used to calculate the standard deviation of crossfall (STDCF) for $100 \mathrm{~m}$ segments in the same manner. Careful examination of the two data sets indicated the following:

- Of Vicroads' $100 \mathrm{~m}$ sections, 62 have HATI values $>1.7 \mathrm{~m} / \mathrm{km}$.

- These sections were found to be at the same locations identified by the drivers.

- $50 \%$ of them are associated with high STDdiff values.

- Of NZ's $100 \mathrm{~m}$ sections, 73 have HATI values $>1.7 \mathrm{~m} / \mathrm{km}$.

- These sections closely matched the locations identified by the driver.

- $70 \%$ of these sections have high STDdiff values.

- Assessment of their geometric characteristics showed that $60 \%$ of them are located in areas with high variation in crossfall and curvature and high gradients. The remaining $40 \%$ of these sections have no geometric problems. The poor rideability of the latter sections is believed to be caused by the vertical vibrations excited by long and medium wavelength roughness, which are developed as a result of subgrade soil settlement or poor longitudinal alignment.

- For both data sets the majority of sections with HATI values $>1.7 \mathrm{~m} / \mathrm{km}$ have IRI values $>3 \mathrm{~m} / \mathrm{km}$ and a great proportion of them have IRI values $>3.5 \mathrm{~m} / \mathrm{km}$ as shown in Fig. 6 . 


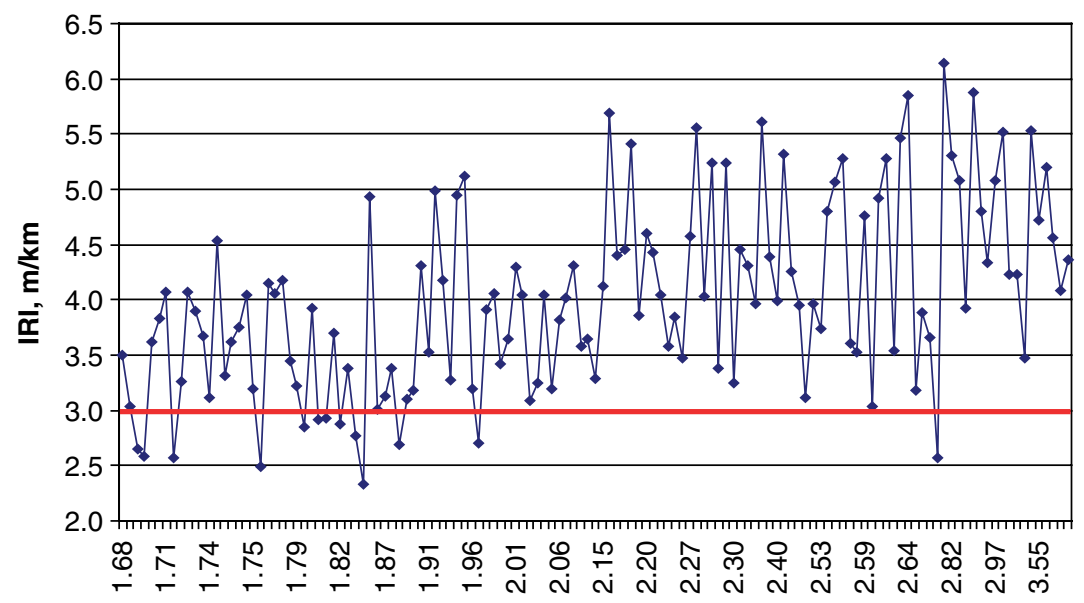

HATI, m/km

Figure 6: IRI values for sections with HATI values greater than the threshold, $1.7 \mathrm{~m} / \mathrm{km}$.

\subsection{Assessing the contributions of geometric characteristics and roughness variation}

Road surface roughness and geometric characteristics that may contribute to the deteriorated ride include roughness variation within and between the two wheel paths, curvature, superelevation, crossfall and gradient. Roughness variation within and between the two wheel paths of a section and crossfall variation have the following effects:

- Longitudinal elevation variations along the wheel paths of a section present vertical excitation (body bounce and pitch) input to the vehicle body and can be represented by the standard deviation of average roughness (STDave) of the two wheel paths.

- The rotational roll and pitch input to the vehicle body could be represented by the standard deviation of crossfall (STDCF) and the standard deviation of the difference in roughness between the two wheel paths (STDdiff).

The STDave, STDdiff and STDCF for each $100 \mathrm{~m}$ segment of the NZ data set were used with other variables including crossfall (CF \%), curvature (inverse of horizontal curve radius, $\mathrm{m}^{-1}$ ) and longitudinal gradient (Grade \%) to develop a regression model. Multiple regression analysis was used to evaluate how these variables relate to drivers' perceptions represented by $\mathrm{TRN}_{\mathrm{HATI}}$ and to assess their contributions. The values of $\mathrm{TRN}_{\mathrm{HATI}}$ were calculated using HATI values of the sections and applying the model shown in eqn (2).

Table 2 presents the parameters of the best model for this data set. The results indicate that the contributions of curvature, absolute values of crossfall and longitudinal gradient are not significant (at 95\% confidence level) and were excluded from the model. The variable STDave is the most significant contributor (high partial r) followed by STDdiff then STDCF. This model explains about $69 \%$ of the variation in $\mathrm{TRN}_{\mathrm{HATI}}\left(\mathrm{r}^{2}=0.69\right)$. The contributions of the different variables can be assessed by squaring the relevant (partial $\mathrm{r}$ ) value. They are: STDave $=42 \%$, STDdiff $=15 \%$ and $\mathrm{STDCF}=4 \%$. The remainder of the variation in $\mathrm{TRN}_{\mathrm{HATI}}$ is explained by their joint contribution. This model indicates that driver rating of pavement rideability increases (better ride) with decreased roughness variation and STDCF. 
These results indicate that in addition to elevation variation along and between the wheel paths, crossfall variation is an important parameter in assessing pavement rideability as perceived by truck drivers. The variables STDave, STDdiff and STDCF were plotted against the predicted TRN $\mathrm{N}_{\text {HATI }}$ values to identify the threshold values for these parameters that result in $\operatorname{TRN}_{\text {HATI }}$ values $<2.5$. It was found that for STDave and STDdiff (see Fig. 7), the threshold value is 1.5. For STDCF values, the results showed that $60 \%$ of the sections with $\mathrm{TRN}_{\mathrm{HATI}}<2.5$ have $\mathrm{STDCF}>1.5$ and $50 \%$ of them have STDCF $>2$, hence the threshold value was set to 1.5.

\subsection{Assessing suitability of IRI}

Results from a study in Sweden relating whole WBV to surface roughness indicated that a roughness level of IRI $>3 \mathrm{~m} / \mathrm{km}$ results in 'uncomfortable' ride in trucks (new and old) at $75 \mathrm{~km} / \mathrm{h}$ and in a highspeed ambulance [10]. The Swedish study also showed that the excitation of WBV in road vehicles riding rough roads is largely caused by crossfall variation and LWR. PSD plots of the vibration series showed that high levels of vibration energy occur at low frequencies, excited by LWR [10].

An IRI value $>3 \mathrm{~m} / \mathrm{km}$ was found to have a $65 \%$ success rate in highlighting sections, of the validation set, with HATI $>1.7 \mathrm{~m} / \mathrm{km}$. However, no specific criterion was established or observed to signify these sections, which makes further investigations essential to establish the cause of ride

Table 2: Best multiple regression model for NZ data set.

\begin{tabular}{lcccccccc}
\hline & \multicolumn{2}{c}{$\begin{array}{c}\text { Unstandarised } \\
\text { coefficients }\end{array}$} & \multirow{2}{*}{$\begin{array}{c}\text { Standarised } \\
\text { coefficients }\end{array}$} & & \multicolumn{3}{c}{ Correlations } \\
\cline { 2 - 3 } \cline { 6 - 8 } Variables & $\mathrm{B}$ & Std. Error & Beta & Sig. & Zero-order & Partial & Part \\
\hline Constant & 3.986 & 0.050 & & 0.000 & & & \\
STDave & -0.667 & 0.048 & -0.587 & 0.000 & -0.785 & -0.664 & -0.470 \\
STDdiff & -0.286 & 0.040 & -0.295 & 0.000 & -0.660 & -0.392 & -0.238 \\
STDCF & -0.47 & 0.014 & -0.116 & 0.001 & -0.286 & -0.199 & -0.113 \\
\hline
\end{tabular}



Figure 7: Variation of STDdiff with predicted TRN $\mathrm{HATI}$ 
deterioration i.e. whether it is short or long wavelength roughness. The latter is hard to determine without conducting waveband analysis since IRI is responsive at high and low frequencies with higher responsiveness to the first (Fig. 1).

High contents of short wavelength roughness $(<2 \mathrm{~m}$ long) such as corrugations, potholes and localised depressions result in vertical motion due to excitation of the axle hop vibration mode. IRI would accurately indicate these sections. However, studies have shown that new vehicle design (suspension systems including seat and cabin suspensions) alleviates the vertical vibrations resulting from excitations by these deformations. This indicates that sections with high IRI and low HATI would provide poor ride to vehicles with poor suspension system design. However, the effects of LWR on ride cannot be eliminated by vehicle design but by road works, which would involve special treatments to control moisture migration and soil movement.

\subsection{Summary of analysis results}

The findings of validation analyses are summarised here:

- HATI proved effective in highlighting most of the sections identified by heavy articulated vehicle drivers as providing poor ride quality in expansive soil areas of Victoria.

- HATI is applicable to other regions, soils and climatic conditions. It proved to be effective in highlighting sections that appear rough to heavy vehicle drivers along the coast of the Canterbury region in NZ where mainly non-expansive sediments make up the subgrade soil.

- HATI is more effective than IRI in highlighting candidate sections in Victoria. This is mainly due to its sensitivity to long wavelength roughness, which is a characteristic of pavements built on expansive soils. Long roughness wavelengths are usually associated with high variations in elevation, hence result in high vertical accelerations. WBVs measured on most sections with HATI values more than threshold were greater than $0.7 \mathrm{~m} / \mathrm{s}^{2}$, which corresponds to a fairly uncomfortable ride [1]. Further, the results of multiple regression analysis for NZ data confirmed that the vertical excitation input, attributed to the variation in roughness within the two wheel paths (STDave), has the highest contribution to the deteriorated perceived ride.

- Most sections with HATI $>1.7 \mathrm{~m} / \mathrm{km}$ are associated with high roughness variation (STDdiff $>$ 1.5) between the two wheel paths (both data sets) combined with high crossfall variation $(\mathrm{STDCF}>1.5)$ for some sections (NZ data). These characteristics are responsible for inducing rotational motions due to excitation of body roll and pitch vibration modes.

- Road geometry and roughness variations within and between the two wheel paths have serious implications on how truck drivers perceive pavement rideability. Roughness variation variables were found to have the highest contributions and there is some contribution from crossfall variation. The same variables were identified in a NZ study [3] as the main parameters for highlighting rough sections with almost the same order of significance.

\subsection{Implementation}

Vicroads and other Australian State Road Authorities (ASAR) have adopted HATI in their pavement management systems to identify sections providing poor rideability to heavy transport operators. By adopting HATI and the other diagnostic measures proposed herein, ASRA can:

- provide better level of service to all road users including heavy vehicle drivers,

- ensure asset sustainability by selecting appropriate rehabilitation treatments, and

- reduce emissions and user costs as a result of improved road smoothness. 


\section{HATI AND DYNAMIC WHEEL LOADS}

The interaction between road surface roughness and heavy vehicle body results in dynamic wheel loading (DWL), which increases pavement damage. The magnitude of these loads is dependent on surface roughness level and characteristics in addition to other factors such as speed and heavy vehicle properties. When travelling at normal highway speeds roughness wavelengths, within the frequency band to which HATI QTF is sensitive, excite the low frequency vibration modes of heavy vehicle body such as body bounce and pitch modes. As these modes are considered to be the major contributors to DWL $[4,11,12]$, it was hypothesised that HATI could be a good predictor of the magnitude of DWL and associated pavement damage.

To investigate the effectiveness of HATI in highlighting sections subject to high DWL, simulation of dynamic wheel forces was performed on a subset of the test sections used for developing HATI. The sections were selected to cover a wide range of HATI values that can be found in the original data set. Four pairs of the sections were chosen to have similar IRI values in order to investigate the differences in vehicle dynamic response on such sections. As mentioned before, they are located in expansive soil areas but with different reactivity levels and lie within different climatic zones. They are combined here in two groups and referred to as low and high reactivity regions. Low reactivity region includes sections located in low reactivity soils and within climatic zones that are not prone to having problems. High reactivity region refers to sections built on highly reactive soils and located in problematic climatic conditions i.e. high seasonal moisture variations.

\subsection{Simulation and correlation analysis}

Computer simulations were carried out on the profile data of the selected sections using a full vehicle model to measure the DWL associated with the drive and trailer axle groups. The vehicle model used in the simulation is a prime-mover semi-trailer combination unit with tandem drive and trailer axles, both fitted with airbag suspensions. The simulation results included the distribution of the dynamic wheel forces associated with all axles in the outer (OT) and inner (IN) wheel paths sampled at $0.005 \mathrm{~s}$ intervals. These dynamic wheel forces were reduced to a simple parameter called the Dynamic Load Coefficient (DLC) [13]. The DLC provides a measure of the variation of DWL and is determined as the ratio of the standard deviation of the forces to the mean tyre force [13].

For the purpose of this study, only the forces generated by the leading axles of the tandem drive and trailer axle groups were considered. The DLC value for each section was determined by averaging the DLC values of the two axle groups in both wheel paths. Fig. 8 shows the DLC values for the test sections with similar IRI values. The figure clearly indicates that sections in high reactivity region (high) are associated with higher DLC values than those in low reactivity region (low) as they have higher HATI values.

\subsection{Further analysis}

To establish a reliable regression model that can predict the dynamic performance of the vehicle (represented by the DLC) more data points were required. To achieve this, the profile data of each test section was divided into $100 \mathrm{~m}$ subsections resulting in a total of 31 sections. Their HATI and IRI values in both wheel paths and their averages were determined. Knowing the simulation speed, $100 \mathrm{~km} / \mathrm{hr}(27.78 \mathrm{~m} / \mathrm{s})$, it was also possible to calculate the DLC values for each $100 \mathrm{~m}$ subsection of the test sections from the original dynamic forces signals. The original signal (load vs time) of each section was divided into segments of 3.6 seconds, then the mean and standard deviation of the loads for each segment were calculated to produce the DLC. 
The DLC average values for the test sections were correlated with the corresponding HATI and IRI values. The correlation coefficients are presented in Table 3 for all sections combined, and when grouped by region reactivity level. These results indicate that both HATI and IRI are good indicators of pavement sections subject to high DWL in low reactivity regions. HATI is a better predictor of pavement damage due to DWL, represented by the DLC than IRI as it can explain $90 \%$ of the variation in DLC compared to the $85 \%$ explained by the IRI. Both models were found to be significant at $95 \%$ confidence level. On the other hand, both HATI and IRI proved to be poor indicators of the dynamic behaviour of road pavements in high reactivity regions.

Further analysis was undertaken to test other profile-based indices as predictors of DLC. They included a number of 4-pole butterworth band pass filters in the wavebands of interest. The butterworth band-pass filter is defined by the short and long wavelengths where the filter gain is 0.707 as shown in Fig. 9a. The output of the filter is reduced to yield RMS slope value called Profile Index $\left(\mathrm{PI}_{\mathrm{b}}\right)$. The $\mathrm{PI}_{\mathrm{b}}$ values of the two wheel paths are averaged using a similar formula to eqn (1). The wavebands tested cover the frequency bands where the peak forces were observed in the DWL spectra for all sections as can be seen in Fig. 9b for one section. These frequency bands are described here. The subscript next to $\mathrm{PI}_{\mathrm{b}}$ of each band represents the relevant vibration mode of the waveband.

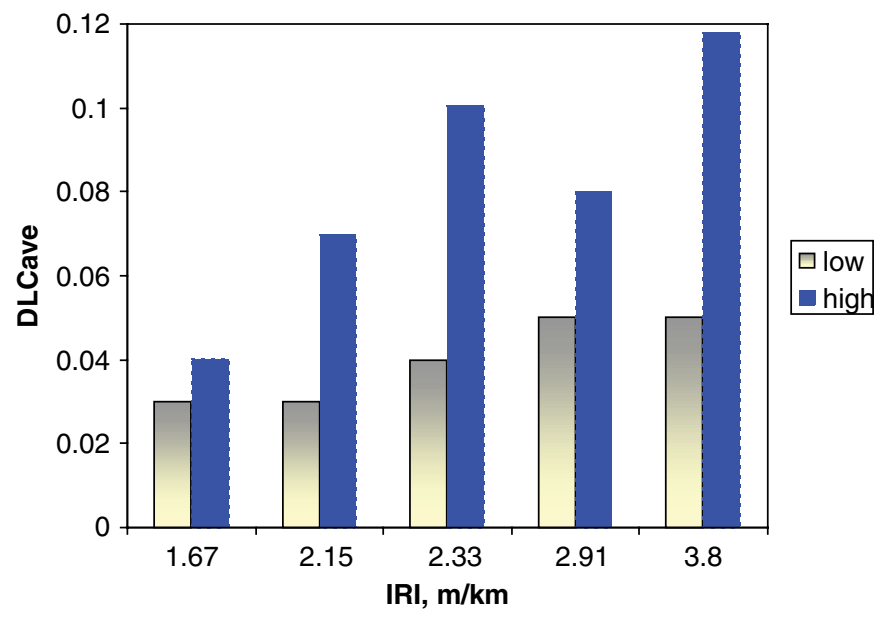

Figure 8: DLC values for sections with similar IRI values.

Table 3: Correlation results between HATI, IRI and the DLC.

DLCave

\begin{tabular}{lccc} 
Variable & All, $\mathrm{n}=31$ & Low, $\mathrm{n}=16$ & High, $\mathrm{n}=15$ \\
\hline IRI & 0.46 & 0.88 & 0.42 \\
$\mathrm{HATI}$ & 0.60 & 0.92 & 0.46 \\
$\mathrm{PI}_{\mathrm{dwl}}=\sqrt{\mathrm{PI}_{\mathrm{br}}+\mathrm{PI}_{\mathrm{bb}}}$ & 0.81 & 0.93 & 0.88 \\
$\mathrm{PI}_{\mathrm{dwl}}=\sqrt{\mathrm{PI}_{\mathrm{br}}+\mathrm{PI}_{\mathrm{bb}}+\mathrm{PI}_{\mathrm{ba}}}$ & 0.71 & 0.94 & 0.69 \\
\hline
\end{tabular}






(a)

(b)

Figure 9: (a) Butterworth band pass filter and (b) dynamic wheel loads spectrum for a test section.

- $\mathrm{PI}_{\mathrm{br}}=$ profile index $\left(\mathrm{PI}_{\mathrm{b}}\right)$ in body roll $(\mathrm{r})$ frequency band $0.4-0.8 \mathrm{~Hz}$, wavelengths at $100 \mathrm{~km} / \mathrm{hr}=$ 34.7-69.4 m

- $\mathrm{PI}_{\mathrm{bb}}=$ profile index in body bounce and pitch (b) frequency band $1.5-4 \mathrm{~Hz}$, wavelengths at $100 \mathrm{~km} / \mathrm{hr}=6.94-18.52 \mathrm{~m}$

- $\mathrm{PI}_{\mathrm{ba}}=$ profile index in axle hop (a) frequency band 8-15 Hz, wavelengths $=1.85-3.47 \mathrm{~m}$

The DWL index, $\mathrm{PI}_{\mathrm{dw}}$, which is determined by taking the square root of the sum of roughness contents in two frequency bands represented by the RMS of $\mathrm{PI}_{\mathrm{br}}$ and $\mathrm{PI}_{\mathrm{bb}}$ proved to be the best predictor for low $\left(r^{2}=0.90\right.$, similar to HATI $)$ and high $\left(r^{2}=0.83\right)$ reactivity regions and for all sections $\left(\mathrm{r}^{2}=0.80\right)$, refer to Table 3 . Adding roughness content in the frequency band of $\mathrm{PI}_{\mathrm{ba}}$ improved the predictions $\left(r^{2}=0.93\right)$ for low reactivity sections only. All these models were developed using power transformation and were found significant at $95 \%$ confidence level.

These results indicate that the contribution of the high frequency excitation (axle hop) to DWL is only significant for sections in low reactivity regions. However, the contribution of the low frequency (body bounce and pitch) excitations is significant for all the test sections considered herein. Further, the results indicate that the contribution of body roll excitation is only significant for sections in high reactivity regions. The profile characteristics of these sections were examined carefully and it was found that they are associated with high variations in profile elevation between the two wheel paths, as can be seen in Fig. 10 for one of the test sections. This variation results in exciting the body roll motion, which occurs at very low frequencies $(0.4-0.8 \mathrm{~Hz})$ for the simulation vehicle. However, further testing is required before a final conclusion can be drawn regarding the contribution of body roll.

\section{CONCLUSIONS}

This paper provided a description of the methodology and outcomes of a research project to address the problems of pavement rideability as perceived by heavy vehicle operators. Road surface characteristics that affect the comfort and perception of heavy vehicle drivers were found to include high contents of LWR only or combined with high roughness variation between the wheel paths 


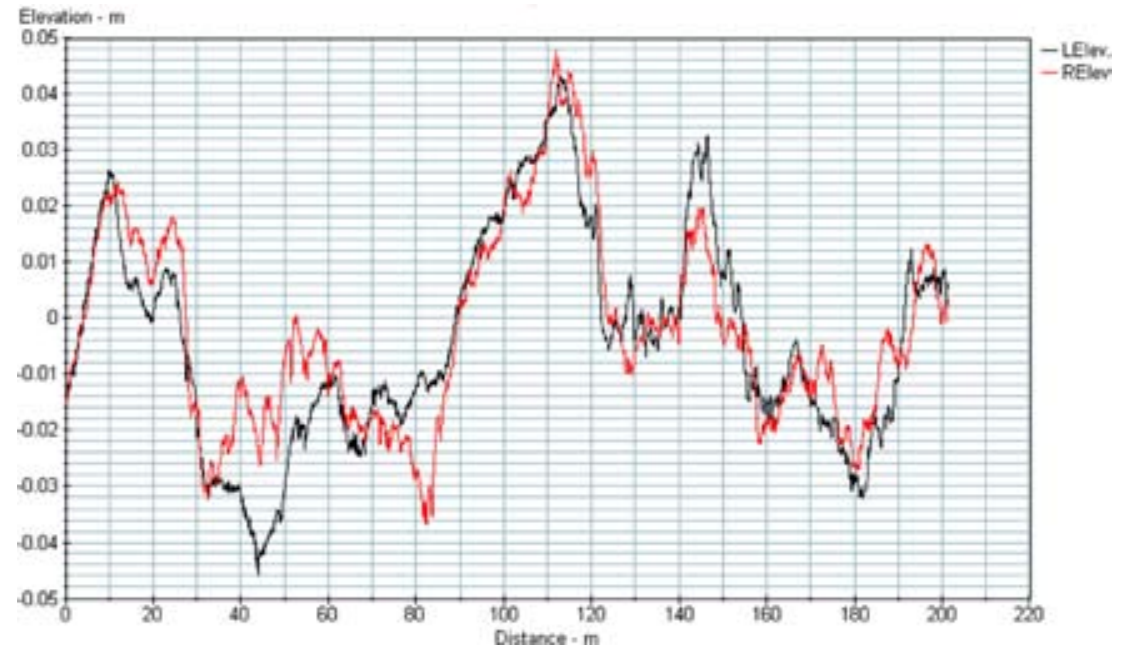

Figure 10: Elevation profiles in the outer (LElev.) and inner (RElev.) wheel paths for a test section.

and/or high variation in crossfall. Long roughness wavelengths are associated with high elevation variations that induce vertical and longitudinal motions due to excitation of body bounce and pitch vibration modes. Variation in roughness between the two wheel paths and crossfall variation induce longitudinal and sideway motions due to excitation of body roll and pitch vibration modes. LWR occurs as a result of subgrade soil movement due to settlement of soft soils or differential movement of expansive soils due to seasonal moisture variation.

A profile based index called HATI has been developed to identify sections providing poor ride to heavy vehicle occupants. HATI is a distance-domain index and easy to determine, which makes it suitable for pavement management at a network level. Validation analysis using two data sets from New Zealand and Victoria proved that HATI is effective in identifying such sections in different regions, soil types and climatic conditions. The analysis also showed that climate and reactivity of the subgrade soil have great influence on roughness characteristics of pavement surfaces and their dynamic interaction with heavy vehicles. Sections in high reactivity regions are associated with high contents of LWR and ultimately high HATI values and subject to high DWL.

Limited analysis also showed that HATI is effective in identifying sections subject to high DWL in areas with low reactivity soils and located in climatic zones that are not prone to having problems. Analysis of the simulated DWL also showed that most of the contribution to DWL, of the test sections in high reactivity regions, is attributed to excitation of the low frequency body bounce, pitch and roll vibration modes. A new DWL index, $\mathrm{PI}_{\mathrm{dwl}}$, proved to be a better predictor of DWL induced damage for all the sections tested herein. The adoption of such index is beneficial to road authorities as it removes the need for using simulation programs in identifying road sections subject to high DWL. The proposed DWL index however, requires validation and further simulation studies to test its applicability to other representative fleet vehicles.

Vicroads and other Australian State Road Authorities have adopted HATI in their pavement management systems to identify sections providing poor rideability to heavy transport operators. Adopting HATI and the other diagnostic measures proposed herein helps road authorities implement appropriate maintenance strategies to ensure the sustainability of their pavement assets and reduce 
emissions generated by heavy and light vehicles, in addition to providing acceptable level of service to all road users.

The findings of this study are applicable to heavy articulated trucks, in particular, prime-mover semi-trailer combination units. However, the methodology is transferable and could be applied to other freight transport vehicles but the results need to be validated using subjective assessment surveys.

\section{REFERENCES}

[1] Hassan, R., Assessment of Road Roughness Effects on Heavy Vehicles on State Highways in Victoria/Australia, PhD Thesis, Swinburne University of Technology: Melbourne, Australia, 2003.

[2] Austroads, A Road Profile Based Truck Ride Index (TRI), AP-R177/00, Austroads: Sydney, Australia, 2000.

[3] Jamison, N.J. \& Cenek, P., Validation of a Proposed Truck Rotational Response Model, Central Laboratories Report 02-529706.00, Opus International Consultants Limited: New Zealand, 2002.

[4] Papagiannakis, A.T. \& Gujarathi, M.S., Roughness model describing heavy vehicle-pavement interaction. Transportation Research Record, 1501, pp. 50-59, 1995.

[5] Cebon, D., Interaction between Heavy Vehicles and Road (The 39th L. Ray Buckendale Lecture), SAE: Pennsylvania USA, 1993.

[6] Sweatman, P. \& McFarlane, S., Investigation into the Specification of Heavy Trucks and Consequent Effects on Truck Dynamics and Drivers, Final Report, Federal Office of Road Safety: Australia, 2000.

[7] International Standard Organisation (ISO) 2631-1, Mechanical Vibration and Shock Evaluation of Human Exposure to Whole Body Vibration, Part 1 General Requirements, 2nd edn, International Organization for Standardisation, 1997.

[8] Cramer, D., Fundamental Statistics For Social Research, step-by-step calculations and computer techniques using SPSS for Windows, Routledge, London/New York, 1998.

[9] Sayers, M.W. \& Karamihas, S.M., The Little Book of Profiling, The University of Michigan, Transportation Research Institute: USA, 1998.

[10] Granlund, J., Ahlin, K., \& Lundström, R., Whole Body Vibration When Riding on Rough Roads, Vagverket Publication 2000: 31E, Sweden, 2000.

[11] Cebon, D., Handbook of Vehicle Road Interaction, Swets \& Zeitlinger Publishers: London, 1999.

[12] De Pont, J., Road Profile Characterisation, Transit New Zealand Research Report No. 29, 1994.

[13] Sweatman, P.F., A Study of the Dynamic Wheel Forces in Axle Group Suspensions of Heavy Vehicles, ARRB Special Report No. 27, 1983. 